\title{
Studies on Chemically Synthesis of Polycrystalline CdTeO3 Thin
} Films

\author{
Ramesh S. Kapadnis ${ }^{1}$, Sampat S. Kale ${ }^{2}$, V. G. Wagh ${ }^{3}$ \\ ${ }^{I}$ Material Research Laboratory, K.T.H.M. College, Nashik 422 002, (India) \\ ${ }^{2}$ M.V.P.'s Arts, Science \& Commerce College, Dindori, 422209 Nashik (India). \\ ${ }^{3}$ K. V. N. Arts, Science \& Commerce College, Nashik 422002 (India)
}

\begin{abstract}
Polycrystalline cadmium telluride oxide $\left(\mathrm{CdTeO}_{3}\right)$ thin films have been achieved by Chemical synthesis process and annealed at $300^{\circ} \mathrm{C}$ in air. XRD of films shows the peaks corresponding to single phase face centered cubic polycrystalline $\mathrm{CdTeO}_{3}$. The compressive strain energy of the film is $0.02569 \mathrm{~J}$ calculated by angle of contact. Optical absorption study revealed that $\mathrm{CdTeO}_{3}$ is a direct band gap of $2.3 \mathrm{eV}$ for the film annealed at $300^{\circ} \mathrm{C}$ and it is effect of oxygen concentration of the deposited material. The resistivity of the films was decreases with increase the temperature.
\end{abstract}

Keywords: - Chemical synthesis, cadmium telluride oxide, strain energy.

\section{INTRODUCTION}

Semiconductor Oxides thin films have number of practical applications in the different devices, for the fabrication of field effect transistors [1] and surface passivation[2]. Thin films of group of II- VI are generally used in many semiconducting compounds which are used in many semiconductor devices because of their optoelectronic properties and the development of flexible and light weight solar cells which are highly stable[34]. Due to wide energy band gap of semiconductor oxides, they can be considered as absorbent layers even in the ultraviolet region and used for optoelectronic applications[5]. A polycrystalline cadmium telluride thin film is one of the most promising low cost candidates for the terrestrial applications. The studies on cadmium telluride and its oxides are very important compound because of its technological importance because they may the part of semiconductor device structures with specific functionality. It is direct band gap material with high absorption coefficient [6-7]. Cadmium telluride oxides can be obtained with controlled energy band gap available values higher than $1.5 \mathrm{eV}$ for $\mathrm{CdTe}[8]$ and upto $\sim 3.8 \mathrm{eV}$ accoding to oxygen concentration[1]. The addition of oxygen to CdTe at dopent level has been aimed to improve the stability of CdTe-based photovoltaic devices [9-12]. Not much work has been done on $\mathrm{CdTeO}$ material till few researchers pay their attention on $\mathrm{CdTeO}$. The synthesis of Oxygenated CdTe films has been reported by different techniques as pulse laser deposition [10], R.F. sputtering [5, 13] etc. Some researcher have conclude that tellurium oxygen (Te-O) bonds were associated with $\mathrm{CdTeO}[5-14]$ and other researchers conclude that it is co-existence of $\mathrm{CdTe}_{2} \mathrm{O}_{5}$ [15] but more groups also available with different composition $[1,16]$. In this communication we report and analyzed For the present work, Chemical bath deposition (CBD) method was used for deposition of the films, as it is a simple, convenient for the large area deposition, capable of yielding good quality films, it forms ion-by-ion formation, controlled thickness by varying time and the most important is, it does not requires sophisticated instrumentations.

In the present paper, polycrystalline oxygenated thin films of CdTe were deposited at room temperature on glass substrate by $\mathrm{CBD}$ and annealed at $300^{\circ} \mathrm{C}$. The morphological, structural and optical properties of annealed films were studied.

\section{EXPERIMENTAL}

Polycrystalline $\mathrm{CdTeO}_{3}$ thin films have been deposited on glass substrates by CBD method from aqueous solution of $0.1 \mathrm{M} \mathrm{CdSO}_{4}, 0.1 \mathrm{M} \mathrm{Na}_{2} \mathrm{TeO}_{3}$ and $20 \%$ of ammonia used as a complexion agent prepared in doubled distilled water. There were no further treatments on the chemicals. Both solutions of $\mathrm{CdSO}_{4}$ and $\mathrm{Na}_{2} \mathrm{TeO}_{3}$ were taken independently in different containers, they were clear solutions. When both solutions were mixed together, white precipitate formed in container. Before dipping the glass substrates into mixtent solution, ammonium hydroxide added drop-by-drop into precipitate and the precipitate completely dissolves and the solution becomes clear. The glass substrates were cleaned with lebolene solution and by ultrasonic cleaner with doubled distilled water for removal of contaminants from the surface of the films. These cleaned glass substrates were mounted on substrate holder and immersed into the solution for deposition at room temperature for different time intervals. The deposited films were homogeneous without cracks and off white in colored. The deposited film dried later in air and annealed at $300^{\circ} \mathrm{C}$ for 2 hours. The annealed films were characterized by 
different techniques as X-ray diffraction (XRD) micrographs were obtained by using X-ray diffractometer (XRD Rigaku D/max-2400 with $\mathrm{Cu}-\mathrm{K} \alpha=0.154 \mathrm{~nm}$ ) at $40 \mathrm{kV}$ with $35 \mathrm{~mA}$ and the scanning rate $0.02^{0}$ with counting time of $8 \mathrm{~s}$. UV-VIS-NIS spectrophotometer (Hitachi 330, Japan) was used to record optical absorption spectra at room temperature angle of contact on substrate were used for calculating the strain energy on the films.

\section{RESULTS AND DISCUSSION}

$\mathrm{CdTeO}_{3}$ films have been deposited by using cadmium sulphate $\left(\mathrm{CdSO}_{4}\right)$ as a source of $\mathrm{Cd}$ ions and sodium telluride as a source of Te. Ammonium hydroxide is a complexion agent for adherence and to adjust the $\mathrm{pH}$ of reaction bath.

The kinematics of the film formula can be understood from following reaction.



From eq ${ }^{\mathrm{n}}(1)$ and (2),

$\mathrm{TeO}(\mathrm{OH})_{2}+\mathrm{Cd}^{2+}+2 \mathrm{OH}^{-} \rightarrow \mathrm{CdTeO}_{3}+2 \mathrm{H}_{2} \mathrm{O}$

Figure 1 represents the structural analysis of annealed $\mathrm{CdTeO}_{3}$ films on glass substrates, the crystalline structure of the sample in the lower part of figure and it shows low intensity peaks on diffractogram. The peaks appearing at $2 \theta$ angles (23.3) and (30.3) with (100), (102) planes respectively were single phase face-centered cubic in nature and they were good agreement with JCPDS card No.80-0090 of CdTe. The diffraction features were observed which having greater intensities with sharp picks at (33.2), (38.3) and (55.3) and these peaks are of oxygenated CdTe and they were good agreement with JCPDS card No.77-1906 of oxygenated CdTe. However R.C. Rodriguez et al [2] reported the films of $\mathrm{CdTeO}_{3}$ are single phased face-centered

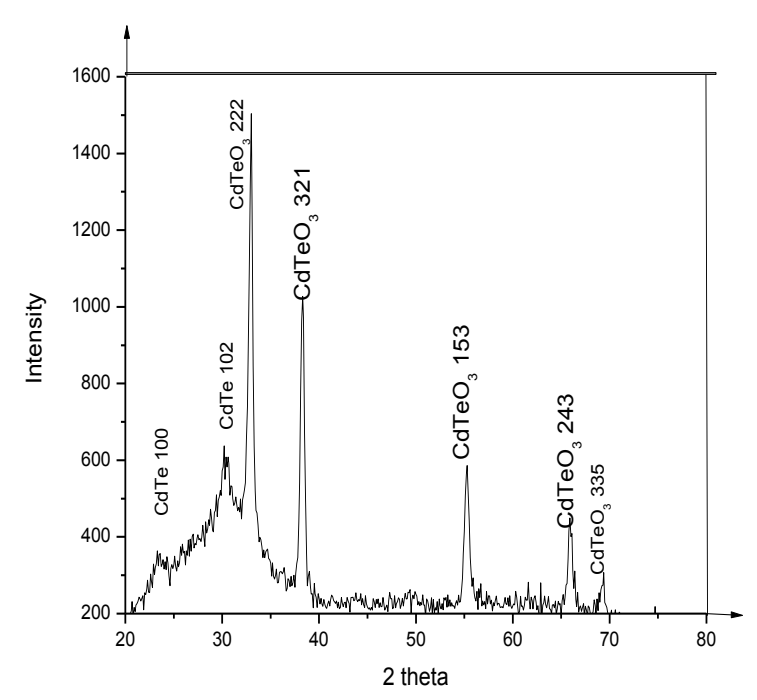

Figure 1- XRD of $\mathrm{CdTeO}_{3}$ on glass substrate of annealed film at $300^{\circ} \mathrm{C}$.

cubic. The diffraction peaks of $\mathrm{CdTeO}_{3}$ can be clearly identified and these results well agree with F.J. Beltrant et al [13] and Rhiger et al [17].

The particle size was approximately $3.25 \mathrm{~nm}$ of the deposited film and it is determined by Debye-Scherrer's formula,

$$
\mathrm{t}=\frac{K \lambda}{\beta \cos \theta} \quad-----(\mathrm{I})
$$

where, $\mathrm{t}$ be the individual crystalline size, $\mathrm{K}$ be Scherrer's constant which is from 0.89 to $0.9, \lambda$ be the wavelength, $\beta$ be the FWHM of the peak and $\theta$ be the Bragg angle. 


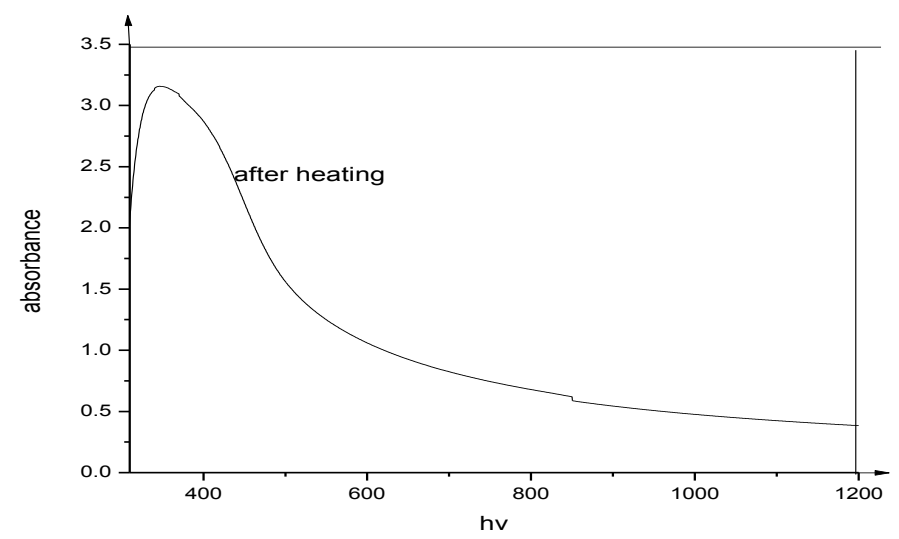

Figure: 2 Absorption spectra of $\mathrm{CdTeO}_{3}$ glass substrate annealed at $300^{\circ} \mathrm{C}$

Optical absorption study (Figure 2) of annealed films on glass substrates were in the wavelength range of 300 to $1200 \mathrm{~nm}$. As the CdTe is a direct band gap material, CdTe oxide can be obtained with band gap values (Figure 3) higher than $1.5 \mathrm{eV}$ for $\mathrm{CdTeO}_{3}$ and it is $2.3 \mathrm{eV}$, according to the oxygen concentration [18-19].



Figure: 3 Plot of $(\alpha h v)^{2}$ verses $h v$ for film on glass substrate



Figure: 4 Contact angle between $\mathrm{CdTeO}_{3}$ films on the glass with water

The band gap shift may be accounted for one or more of the hexagonal to the cubic phase transformation taking place at temperature can reduce the energy band gap of films. The optical absorption behavior of polycrystalline $\mathrm{CdTeO}_{3}$ thin films deposited on glass substrates depends upon the size and the concentration of the CdTe polycrystalline. The angle of contact of the $\mathrm{CdTeO}_{3}$ film (Figure 4) was measured and the surface energy of the film was measured and found $0.02569 \mathrm{~J}$. 




Figure 5 Resistivity of $\mathrm{CdTeO}_{3}$ films during heating and cooling.

\section{CONCLUSIONS}

Chemical bath deposition of $\mathrm{CdTeO}_{3}$ thin films on glass substrates is simplest method for polycrystalline films. $\mathrm{X}$-ray diffraction study revealed that, $\mathrm{CdTeO}_{3}$ films are single face centered cubic structures and polycrystalline in nature. The band gap energy were slightly higher than band gap of CdTe $(\mathrm{Eg}=1.5 \mathrm{eV})$, due to oxygen concentration. SEM micrograph shows the particles was not single crystal grains but it composed of number of crystallites. Surface energy is calculated by angle of contact and it is $0.02569 \mathrm{~J}$. The resistivity of the films (Figure 5) was decreases with increase the temperature.

\section{ACKNOWLEDGEMENT}

Authors are thankful to Board of College and University Departments, University of Pune for their financial support.

\section{REFERENCES}

[1] A. Z. Navarro, M. Z. Torres, V. Sosa, P. B. Perez, J. L. Pena, J. Vac. Sci. Technol. A 12 (1994) 714.

[2] R. C. Rodriguez, A. Iribarren, P. B. Perez and J. L. Penna, Thin Solid Films 484 (2005) 100.

[3] S. Lalitha, S. Karazhanov, P. Ravindran, S. Senthilrasu, R. Satyamoorthy, and J. Janabergenov, Physica B, 387 (2007) 227.

[4] H. H. Contreras, C. M. Garcia and G. C. Puente, Thin Solid Films, 451(2004)203.

[5] A. Iribarren, E. M. Proupin, R. C. Rodriguez, V. Sosa, J. L. Penna and F. C. Briones, J. Appl.Physics, 86 (1999) 4688.

[6] T.L. Chu, S. S. Chu, Progr. Photovolt Res Appl 1(1993) 1-42.

[7] M. Soliman, A. B. Kashyout, M. Shabana, M. Elgamal Renewable Energy 23 (2001) 471-481.

[8] Semiconductors: Other than Group IV Elements and III-V Compounds. Data in Science and Technology, edit. By O. Madelung, Springer, Berlin, Germany, 1992.

[9] E. M. Proupin, G. Gutierrez, E. Palmero, J. L. Pena, Phy. Rev-B 70 (2004) 035112,

[10] M. Y. E. Azhari, M. Azizan, A. Bennouna, A. Outzourhit, E. L. Ameziane, M. Brunel, Thin film Solids, $366(2000) 82$.

[11] F. F. Wang, A. L. Faherenbruch, R. H. Bube, J. Appl. Phys. 65 (1989) 3532

[12] J. C. Rodriguez, R. L. Morales. O. J. Sandoval, F. R. Melgarejo, M. M. Lira, S. J. Sandoval, J. Appli. Phys. 103 (2008) 123516

[13] F. J. Beltran, R. R. Bon, F. G. Hernandez, F. Sanchez, O. Z. Angel, J. G. Mendoza, G. Torres, J. Phys. Condens. Matter 5 (1993) 345.

[14] A. Z. Navarro, M. Z. Torres, V. Sosa, P. B. Perez, J. L. Pena, J. Vac. Sci. Technol. A 12 (1994) 714.

[15] A. B. Christie, I. Sutherland, J.M. Walls Surf. Sci. 135 (1983) 225.

[16] I. H. Calderon, S. J. Sandoval, L. L. Pana, V. Sailer, J. Cryst. Growth 86 (1988) 396.

[17] D. R. Rhiger, R. E. J. of Vac. Sci. Technol, A 1 (1992) 1712.

[18] M. M. Lira, S. J. Sandoval, I. H. Calderson, J. Vaccu. Sci. Tech. 7 (1989) 18218.

[19] N. E. Kadry, M. F. Ahmed, K. A. Hady, Thin Solid Films 274 (1996) 120. 